\title{
Design of Power Conditioning Circuit for Thermal Energy Harvester in Powering a Wireless Sensor Node
}

\author{
Wei Ping Chen, Swee Leong Kok
}

\begin{abstract}
Wireless Sensor Network (WSN) comprises of huge quantity of miniature sensor nodes (SNs) with certain limitation of computer resources which capable for sensing, gathering, data processing and wireless communication. Since most of the SNs are powered by traditional batteries, it can be inconvenient due to their limited lifespan. In this paper, a thermoelectric generator (TEG) is used as thermal energy harvester with the intention to extend the SN lifespan. Since the output voltage generated by this TEG is insufficient to power up the node, a DC-DC step-up converter circuit based on MAX757 integrated circuit is designed to step up the output voltage produced from TEG up to $3 V$. The SN required an average power which is about $25 \mathrm{~mW}$ in the active mode and $60 \mu \mathrm{W}$ when it is in sleeping mode. This node can transmit data whenever there is at least a temperature gradient of $15^{\circ} \mathrm{C}$ between the hot and cold surface of TEG.
\end{abstract}

Keywords: DC-DC step up converter, Thermoelectric generator, Thermal energy harvesting, Wireless Sensor Network (WSN).

\section{INTRODUCTION}

In this modern day, most of the electronic devices and systems included wireless sensor nodes are powered by electrical power source such as battery. In wireless sensor network, these sensor nodes work together to gather, process and communicate with each other by using transceiver. The number of motes in a wireless sensor network capable to be hundreds or even thousands. However, battery's life span is short termed. When the batteries deplete, they need to be replaced over certain period.

In Wireless Sensor Network (WSN), the use of battery as energy source for the sensor nodes can be bothersome due to their restricted lifespans. In remote area, people unable to access the places hence battery replacement is impossible, especially for hazardous environment. Batteries are experiencing current leakages which result in draining of batteries even though these batteries are not in used which make periodic replacements unavoidable. Thus, it may result in high maintenance cost. In this study, energy harvesting technique is implemented to power up the wireless sensor network, a system builds from lots number of wireless sensor

Revised Manuscript Received on July 22, 2019.

Wei Ping Chen, Faculty of Electronic and Computer Engineering, Universiti Teknikal Malaysia Melaka, Hang Tuah Jaya, 76100 Durian Tunggal, Melaka, Malaysia. Email: chenweiping940426@gmail.com

Swee Leong Kok, Faculty of Electronic and Computer Engineering, Universiti Teknikal Malaysia Melaka, Hang Tuah Jaya, 76100 Durian

Tunggal, Melaka, Malaysia. Email: sweeleong@utem.edu.my nodes.

Energy harvesting also knowns as energy searching technique which allows electronics to be power up where there is non-direct incoming power supply. It removes the wire in electronic power system, and eventually abolish and eliminate the replacement of batteries. Energy harvesting is one of the techniques of collecting the waste energy (heat, kinetic, mechanical, light etc.) as the energy becomes available and converting it to useful form of energy that could power up the circuitry. This "free energy" can get from various of sources include solar or light energy could captured by a piezoelectric elements (PZT) and thermal energy could capture by using a thermoelectric generator (TEG).

\section{THERMAL ENERGY HARVESTING}

An evolving technique that capable to overcome the restriction of battery is environmental energy harvesting. This is one of the methods of mining power from surrounding and altering it to form usable electrical energy or refer as energy harvesting [1]. In this project, thermoelectric generator, TEG is used as the primary energy harvester that used to upsurge the life cycle and competency of sensor nodes by enhancing the battery usage. Since TEG has very low efficiency which is about $5-7 \%$ only, it is not very popular and widely used by researcher [2]. Thus, a poer conditioning circuit is required to boost up the output voltage produced by TE [3-5].

Thermoelectric generators are devices could capture the heat energy from surrounding and alter it to the electrical energy by using a phenomenon named "Seebeck Effect". In 1821, Thomas Johann Seebeck found out that thermal gradient can be produced between two metals once the heat is given to one side of the metal and cold side is applied to another side of the metals. The electric current can be generated once there is a temperature difference between the TEG. In other words, temperature difference brings the heat flow and the charge carriers diffuse from hot side to cold side of the metals. Since there is a flow of charge carriers from the hot region to the cold region of TEG, a voltage difference can be produced. The electrons or charge carriers transfer heat in two ways which are by disseminating heat through collision with other electrons and transferring internal kinetic energy during transport.

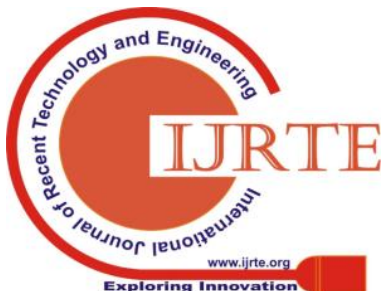


Thermoelectric effect can be known as Seebeck effect, is one of the phenomena involves changing between the electrical energy and heat which is irrevocable. This revocable phenomenon of the Seebeck effect principally occurs at different conductors of junction Besides, limited temperature gradient is existing all over the area of conductors. In overall, Seebeck effect is defined from the formation of an electromotive field.

$$
E_{\text {emf }}=-S \Delta T
$$

where:

$\mathrm{S}$ is Seebeck coefficient, and $\Delta \mathrm{T}$ is temperature gradient which is TH-TC

The power generated by TEG can be calculated by using the formula [6]:

where:

$$
P_{\text {ouT }}=I_{\text {ouT }}^{2} \times R_{\text {Load }}
$$

$\mathrm{P}_{\text {OUT }}$ is power produced by TEG,

$\mathrm{I}_{\mathrm{OUT}}$ is current produced by TEG,

and $\mathrm{R}_{\mathrm{Load}}$ is load resistance that applied

If a heat source is provided, the thermoelectric device may function as a power generator, as in the Fig. 1. The heat source will drive electrons in the n-type element toward the cooler region, thus creating a current through the circuit. Holes in the p-type element will then flow in the direction of the current. The current can then be used to power a load, thus converting the thermal energy into electrical energy [7].

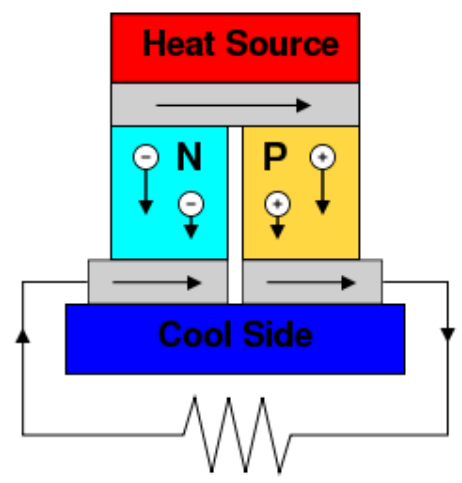

Fig. 1. Diffusion of charge carrier. [7]

Recently, several inventions of the use of thermal energy scavenging technology blooming faster. More researches are moving towards this area or field as there are some successful industrial applications are deploying these technique and promising alternative to batteries for a sustainable system. Seiko TE wristwatch was the first invention or product ever that deployed thermal energy harvesting (TEH) by using a TE module with leg dimensions of $80 \mu \mathrm{m}$ x $80 \mu \mathrm{m}$ x $600 \mu \mathrm{m}$ as a power source in this watch [8]. By using this TE generator, the proposed wristwatch can operate by converting the heat produce by a person's wrist into electrical energy. This module is estimated to generate about $20 \mathrm{mV}$ at a temperature difference of $1 \mathrm{~K}$. In the other hand, Ibragimov et al. [9] move a step ahead where they able to develop a TEG which is directly embedded in aluminum which can generate up to
$500 \mu \mathrm{W}$ of external electric power when the temperature gradient, $\Delta \mathrm{T}$ is balanced at $138^{\circ} \mathrm{C}$. Then, Aneta at el. [10] present a thermal energy harvesting wireless sensor node in aluminum core PCB technology. In his paper, the presented system is compact and mechanically rigid structure with two aluminium PCBs that performs as heat accumulator and spreader. This system succeeded to generate a total of harvested power $2 \mathrm{~mW}$.

Dalola et al. [11] introduced a self-powered sensor system by utilizing thermoelectric energy harvesting technique to generate the heat gradient via hot walled in pipes and a low power temperature sensor to measure the temperature of pipes. This system required at least $8.5^{\circ} \mathrm{C}$ of temperature gradient to run properly. Besides, this system required $0.9 \mathrm{~mW}$ of power with a current consumption of about $0.4 \mathrm{~mA}$. Another application of TEH was presented in [12], where Ali et al. make use of heat gradient generated from low-level source to power up the WSN node. The system that proposed in this paper utilizes two Peltier elements TEC which connected in series to help in increasing the collected voltage up to $2.0 \mathrm{~V}$. The WSN node is designed and required about $50 \mathrm{~mW}$ output power for the system to operate. This node can operate when there is at least temperature gradient of $30^{\circ} \mathrm{C}$. However, when the TEC is cascaded, the system will become less efficient.

The motivation of this paper is to promote green technology since it is environmentally friendly for sustainable development. It reuses most of the wasted energy and convert this waste energy into usable electrical energy which can power up some low power electronic devices. Besides, this system will be easy to install in any system for example industry machine, car engine, home appliance and other application.

\section{EXPERIMENT SET UP}

In order to power up a WSN node with thermal energy harvesting, there are three main factors that should be considered. First is how much energy can be collected by TEG which based on the temperature gradient between the hot and cold sides of TEG; second is how capably the energy can be controlled to the required operating voltage of the circuitry and the third how much the energy consumption of the wireless sensor node.

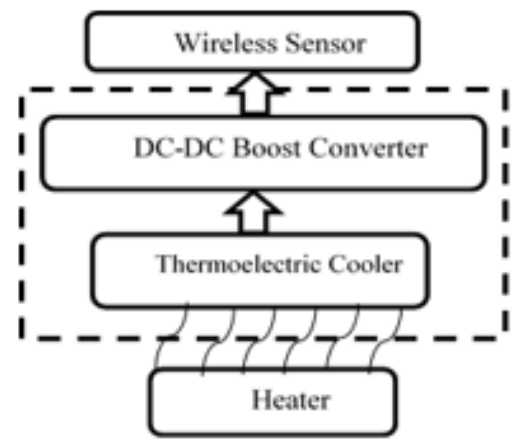

Fig. 2. Illustration of energy harvesting system. 
Fig. 2 shows an illustration of thermal energy harvesting system for a wireless sensor. One surface of TEG is applied heat by placing the heater which acts as hot side and placing the heat sink on the other side of TEG which act as cold side so that it achieves the temperature gradient between TEG. In other words, the TEG is sandwiched between a heat sink and a resistance heater as shown in Fig. 3.
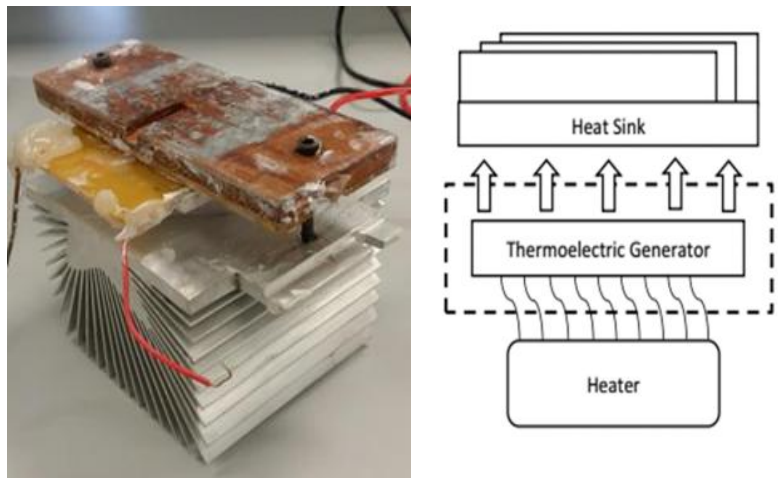

Fig. 3. Assembly set-up of TEG.

A TEC, TEC1-12706 with sizes of 40mm x 40mm x 3.8mm is chosen and functioned as a generator. The resistance heater is designed based on the size of the TEG used in this project to optimize the heat transfer from the heater to the TEG's surface. In addition, thermo-paste is applied to the gaps between the heater and TEG so that it can reduce or minimize the heat loss to surrounding.

The resistance heater is then connected to a power supply to regulate the thermal gradient. This resistance heater is functioned as a heating element as it converts the electric energy form the power supply into heat. In the other hand, a heat sink is used with the intention to dissipate the heat from TEG cold surface and to optimize the thermal gradient created across TEG. As the temperature gradient increase, more harvested voltage can be produced. Thermocouple is used to measure the temperature gradient created between the hot and cold side of TEG. Before a boost converter circuit is designed, TEG characterization is done first to evaluate the output voltage from the. By doing so, a DC-DC boost converter circuit can be constructed based on the output voltage from the TEG. Fig. 4 shows the experiment set up of the TEG characterization.

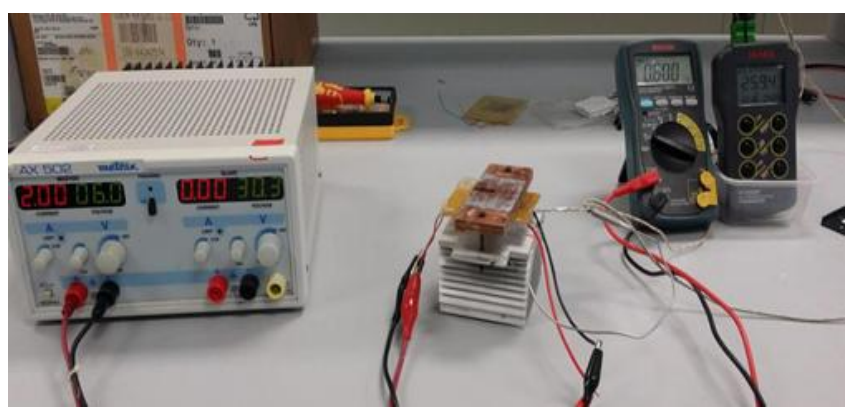

Fig. 4. Experimental set up.

Since the output voltage produced by TEG is too small and it is insufficient to power up the sensor node, a DC-DC boost converter circuit is designed. The output voltage of this DC-DC boost converter circuit was calculated by the equation:

$$
V_{\text {out }}=V_{\text {ref }}\left[\frac{\left(R_{1}+R_{2}\right)}{R_{2}}\right]
$$

These R1 and R2 forms a voltage divider between the output and the FB pin with $\mathrm{VREF}=1.25 \mathrm{~V}$. The large values for R1 and R2 were chosen from $10 \mathrm{k} \Omega$ to $200 \mathrm{k} \Omega$ because the input bias current at FB has a maximum value as large as 100nA. To simply the resistor selection:

$$
\begin{gathered}
R_{1}=R_{2}\left[\left(\frac{\text { Vut }_{\text {out }}}{V_{\text {raf }}}\right)-1\right] \\
R_{1}=(20 \mathrm{k} \Omega)\left[\left(\frac{3.0 \mathrm{~V}}{1.25 \mathrm{~V}}\right)-1\right] \\
\therefore R_{1}=28 \mathrm{k} \Omega
\end{gathered}
$$

Therefore, if we set R2 is $20 \mathrm{k} \Omega, \mathrm{R} 1$ will be equal to $28 \mathrm{k} \Omega$. Since the resistor only available for $27 \mathrm{k} \Omega$ and $30 \mathrm{k} \Omega, 30 \mathrm{k} \Omega$ is chosen because the resistance value is greater than $28 \mathrm{k} \Omega$. Since the chosen R1 does not exact the same as the calculated result, the expected VOUT can be obtained from the DC-DC converter circuit will equal to $3.125 \mathrm{~V}$. In this circuit, MAX757 is an integrated circuit that can operates down to $0.7 \mathrm{~V}$ supply voltage and produces a higher adjustable output voltage in the range from $2.7 \mathrm{~V}$ to $5.5 \mathrm{~V}$. In addition, there are some passive components are also needed for this MAX757 to operate properly.

In this circuit, $22 \mu \mathrm{H}$ inductor was chosen as it has saturation current rating same to or larger than the peak switch current limit which is 1.2A. A Schottky diode, NSR0320MW2T1 was chosen as it has lower forward voltage and higher current. A $100 \mu \mathrm{F}$ capacitor was chosen because it can provide $50 \mathrm{mV}$ output ripple. A smaller capacitor down to $10 \mu \mathrm{F}$ is used for light loads and can tolerate higher output ripple. Fig. 5 shows the circuit diagram and circuit construction of boost converter circuit by using an IC named MAX757.

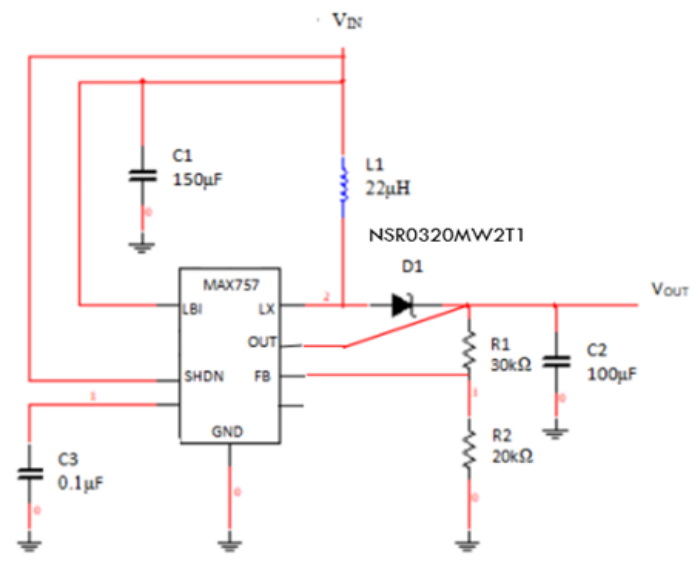

Fig. 5. Circuit diagram.

When the DC-DC converter circuit is completely done, it is integrated with the sensor node. Once the sensor node blinks, it shows that the sensor node has been powered up and turned on. The data received by the sensor node will send to the gateway. 


\section{RESULT AND DISCUSSION}

In the beginning, there are two different model of TEGs were compared which are Laird xc31 (TEG1) and TEC1-12706 (TEG2). Both TEGs were characterized to evaluate the range of the output voltage can produced by TEGs when different temperature gradient was created across the TEGs.

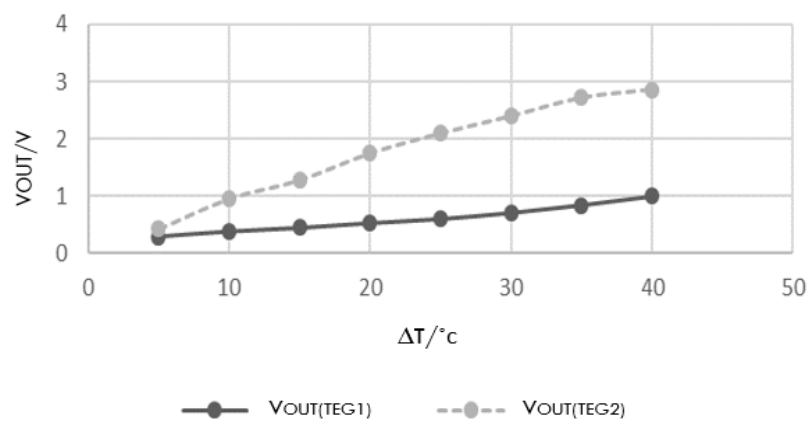

Fig. 6. Output voltage of TEG versus temperature gradient.

Fig. 6 shows that output voltage from both TEGs are directly proportional to the temperature gradient. Besides that, the graphs of the output voltage from both TEG are increasing linearly. At $\Delta \mathrm{T}$ equal to $15^{\circ} \mathrm{C}$, the output voltage that generated by TEG 1 is $0.449 \mathrm{~V}$ whereas the output voltage that generated by TEG 2 is $1.285 \mathrm{~V}$. Based on these two data, it proves that the output voltage generated by TEG 2 is doubled the output voltage generated by TEG 1 .

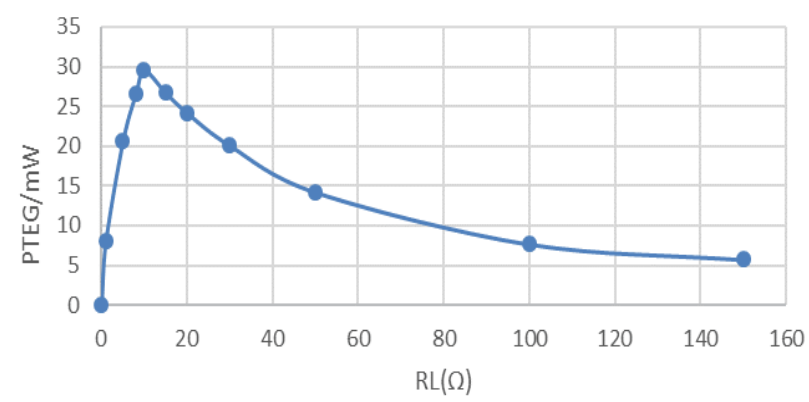

Fig. 7. Output power of TEG.

Figure 7 shows that maximum output produced by TEG is $29.48 \mathrm{~mW}$ when $\mathrm{R}_{\mathrm{L}}=10 \Omega$. It clearly shows that the input power of the boost converter gives the largest when the impedance matching is achieved. Therefore, we expected that, the input power of this boost converter is $29.48 \mathrm{~mW}$ when the temperature gradient between TEG is $15^{\circ} \mathrm{C}$. When the average harvest power surpasses the conversion losses and average sensor node power, the system can function autonomously with an unlimited lifetime.

Then, the input of step-up converter was connected to TEG and the output of DC-DC boost converter was connected to a voltmeter in parallel to measure the output voltage produced by TEG.

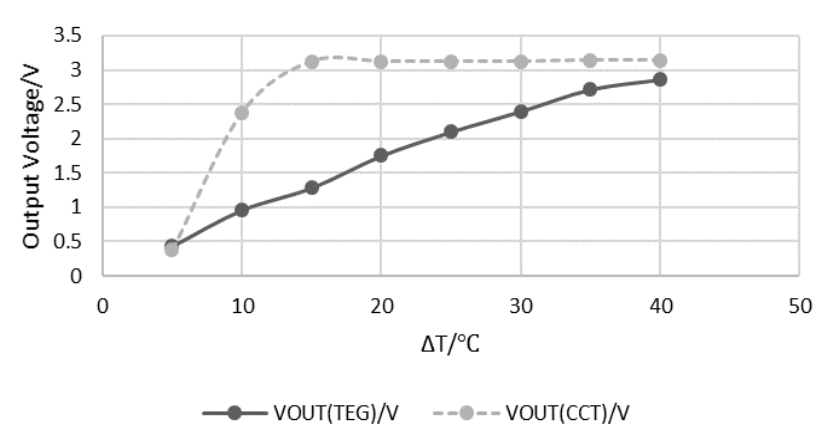

Fig. 8: DC-DC step up graph.

Figure 8 shows the relationship the output voltage produced by TEG and the boost converter circuit with different temperature gradient, $\Delta \mathrm{T}$ which is created between the TEG. This graph also shows the comparison between the voltage before and after being boost up by the DC-DC converter circuit at different $\Delta \mathrm{T}$. Both output voltages are proportional to the temperature gradient created across TEC. The graph of output voltage harvested from TEG is increasing linearly. At the beginning, the output voltage of TEG is almost the same with the output voltage generated by the boost converter. However, the graph of output voltage produced by the circuit increased sharply and then maintained at saturation point.

At $5^{\circ} \mathrm{C}$, the input voltage of the circuit did not step up by the boost converter and almost the same as the output voltage of TEG. This is because the minimum required operating voltage for the circuit is $0.7 \mathrm{~V}$. The output voltage produced by TEG at $5^{\circ} \mathrm{C}$ of $\Delta \mathrm{T}$ was about $0.4 \mathrm{~V}$ which is lower than the minimum requirement operating voltage for the circuit. Once the output voltage produced by TEG reached more than $0.7 \mathrm{~V}$, the circuit was activated and started to step up the voltage supplied from TEG. At $10^{\circ} \mathrm{C}$ of $\Delta \mathrm{T}$, the output voltage of circuit increased from $0.961 \mathrm{~V}$ to $2.378 \mathrm{~V}$. The sudden rise can be observed in the output voltage reading of the circuit when temperature difference keeps increasing until $15^{\circ} \mathrm{C}$ but the voltage seems to saturate in the range from $3.125 \mathrm{~V}$ to $3.143 \mathrm{~V}$. This is due to the integrated circuit (IC) deployed in this power conditioning circuit gives adjustable output. Since the voltage divider is connected to its Feedback pin (FB pin), it provides slightly above $3 \mathrm{~V}$ output.

By comparing the result with [13], TEC1-12706 is also used in this paper, however, the proposed DC-DC power conditioning circuit was able to boost the output voltage produced by TEG to $3 \mathrm{~V}$ when the temperature gradient is around $50^{\circ} \mathrm{C}$. Therefore, more temperature gradient is needed by the TEG to make the circuit to turn on the electronic devices. 


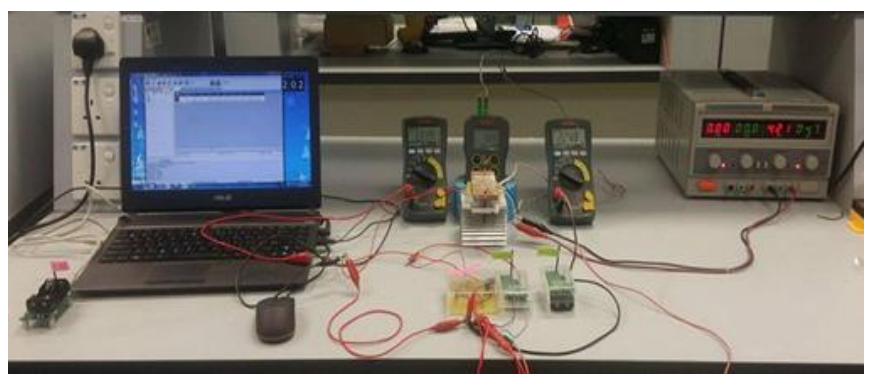

Fig. 9. Sensor data collection.

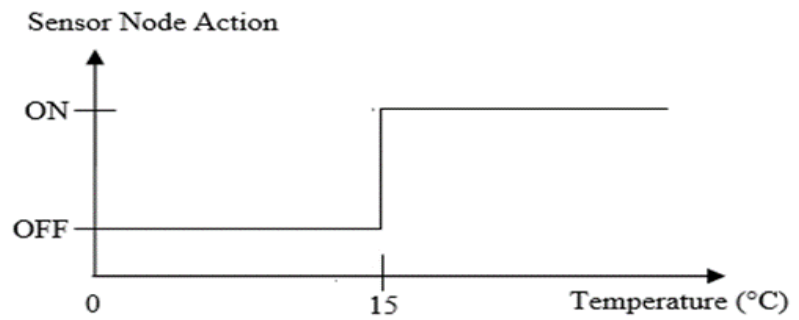

Fig. 10. Sensor node action versus temperature gradient applied on TEG.

Fig. 9 shows the wireless sensor node was operating once the output voltage of TEG reached to $3 \mathrm{~V}$. When the output voltage of TEG is lower than $2.3 \mathrm{v}$, the wireless sensor node will turn OFF. The sensor readings from the sensor node were collected by the base station and showed in the PC. Fig. 10 shows the relationship between sensor node action and the temperature gradient across TEG. When the temperature gradient between TEG is greater than $15^{\circ} \mathrm{C}$, the sensor node will turn ON. Besides, the sensor node will turn OFF when the temperature between TEG is lower than $15^{\circ} \mathrm{C}$.

\section{Conclusion}

In this paper, a self-generated wireless sensor node is successfully developed. The suitable TEG was chosen and characterized, then the results were plotted in graph. After that, output voltage of TEG was boosted up by using DC to DC converter. Therefore, the efficiency of the proposed system is around $80 \%$. The sensor node was turned $\mathrm{ON}$ when the output voltage of boost converter reaches $3 \mathrm{~V}$ at $15^{\circ} \mathrm{C}$ of temperature gradient across the TEG.

\section{ACKNOWLEDGMENT}

The authors would like to acknowledge the support of this work by Skim Zamalah UTeM provided by Universiti Teknikal Malaysia Melaka, as well as the facility supported by Faculty and Advanced Sensor and Embedded Control Systems (ASECs) Research Group, CeTRI sponsored by UTeM-Industry Matching GLUAR/ IMPRESSIVE/2017/ FKEKK-CETRI/I00024.

\section{REFERENCES}

1. A. Garg, R. K. and M. Pandey, "Review of Energy Harvesting Techniques for Wireless Sensor Nodes", Communications on Applied Electronics, vol. 5, no. 7, pp. 1-4, 2016.

2. O.A. Mohammad, "Applied Energy: An Introduction. Thermoelectric and Thermionic Energy Conversion", pp.360-262, 2013.

3. C. C. Law, H. Wahid and P. L. Leow, "A charge pump-based power conditioning circuit for low powered thermoelectric generator (TEG)", 2015 10th Asian Control Conference (ASCC), 2015.

4. M. Abdulqader, A. Mohammad, M. Baker, S. Hani and I. Mohammed, "A multi-input, multi-output power management unit using dickson charge pump for energy harvesting applications", 2016 IEEE 59th International Midwest Symposium on Circuits and Systems (MWSCAS), 2016.

5. J. Lopera, H. Rodriguez, J. Pereira, A. de Castro and J. Vigil, "Wireless sensors supplied by energy harvesting thermoelectric generators", 2016 IEEE Industry Applications Society Annual Meeting, 2016.

6. B. K. Rajeh and B. Kiran, "Development of prototype for waste heat energy recovery from thermoelectric system at Godrej vikhroli plant IEEE Conference Publication", Ieeexplore.ieee.org, 2018. [Online]. Available: http://ieeexplore.ieee.org/document/7029943/.

7. "Thermoelectric effect - New World Encyclopedia", Newworldencyclopedia.org, $2017 . \quad$ Available: http://www.newworldencyclopedia.org/entry/Thermoelectric_effect.

8. M. Kishi, H. Nemoto, T. Hamao, M. Yamamoto, S. Sudou, M. Mandai and S. Yamamoto, "Micro thermoelectric modules and their application to wristwatches as an energy source", Eighteenth International Conference on Thermoelectrics. Proceedings, ICT'99 (Cat. No.99TH8407).

9. A. Ibragimov, H. Pleteit, C. Pille and W. Lang, "A Thermoelectric Energy Harvester Directly Embedded Into Casted Aluminum", IEEE Electron Device Letters, vol. 33, no. 2, pp. 233-235, 2012.

10. A. Prijic, L. Vracar, D. Vuckovic, D. Milic and Z. Prijic, "Thermal Energy Harvesting Wireless Sensor Node in Aluminum Core PCB Technology", IEEE Sensors Journal, vol. 15, no. 1, pp. 337-345, 2015.

11. S. Dalola, V. Ferrari, M. Guizzetti, D. Marioli, E. Sardini, M. Serpelloni and A. Taroni, "Autonomous Sensor System With Power Harvesting for Telemetric Temperature Measurements of Pipes", IEEE Transactions on Instrumentation and Measurement, vol. 58, no. 5, pp. 1471-1478, 2009.

12. A. Abdal-Kadhim and K. Leong, "Application of thermal energy harvesting from low-level heat sources in powering up WSN node", 2017 2nd International Conference on Frontiers of Sensors Technologies (ICFST), 2017.

13. R. Hazli, A. H. Hamidon, M. Y. Azdiana, A. A. Latiff, H. H. M. Yusof and W. H. M. Saad, "Design of DC-DC Boost Converter with Thermoelectric Power Source", International Journal of Advance Research in Electrical, Electronics and Instrumentation Engineering, vol. 2, no. 9, pp. 4170-4177, 2013.

\section{AUTHORS PROFILE}

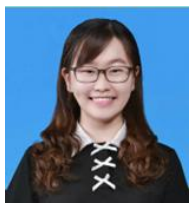

Wei Ping, Chen received her Bachelor degree in electronice and computer engineering from Universit Teknikal Malaysia Melaka (UTeM) in 2108, exploring energy harvesting and embedded system design. She is currently pursuing the M.Eng. degree at the same university, UTeM. Her research interest includes embedded system design and WSN design based therma energy harvesting. She has involved in some projects related to WSN based energy harvesting for environmental monitoring system.

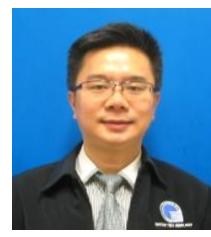

Swee Leong, Kok was awarded Ph.D in Electronics and Electrical Engineering from the University of Southampton, UK in 2010, exploring thick-film technologies for fabricating piezoelectric energy harvesting devices. Dr. Kok has been a lecturer in Universiti Teknikal Malaysia Melaka (UTeM) since 2003 after completing his MSc degree in Electrical, Electronic and System Engineering from Universiti Kebangsaan Malaysia (UKM), researching on optical planar waveguide fabrication and characterization. $\mathrm{He}$ is currently an Associate Professor and also research leader of Advanced Sensors and Embedded Control Systems (ASECs) Research Group under the Center of Telecommunication and Innovation (CeTRI), Universiti Teknikal Malaysia Melaka. He has been author and coauthor for more than 50 publications and reviewing IEEE, IOP, Elsevier and other Scopus indexed journals. His research interest is related to energy harvesting system and applications, MEMS, and thick-film devices fabrication technologies for the application of sensing, actuating and self-powering for wireless sensor network. 